\title{
Assessing changes in wind erosion climatic erosivity in China's dryland region during 1961-2012
}

\author{
YANG Fengbo ${ }^{1,2}$, LU Changhe ${ }^{1}$ \\ 1. Key Laboratory of Land Surface Pattern and Simulation, Institute of Geographic Sciences and Natural Re- \\ sources Research, CAS, Beijing 100101 China; \\ 2. University of Chinese Academy of Sciences, Beijing 100049, China
}

\begin{abstract}
China's dryland region has serious wind erosion problem and is sensitive to climate change due to its fragile ecological condition. Wind erosion climatic erosivity is a measure of climatic factors influencing wind erosion, therefore, evaluation of its intensity and response to recent climate changes can contribute to the understanding of climate change effect on wind erosion risk. Using the FAO equation, GIS and statistical analysis tools, this study quantified the climatic erosivity, analyzed its spatiotemporal variations, and detected the trend and sensitivity to climate factors during 1961-2012. The results indicate that mean annual climatic erosivity was 2-166 at 292 stations and $237-471$ at 6 stations, with the spatial distribution highly in accordance with wind speed $\left(R^{2}=0.94\right)$. The climatic erosivity varied greatly over time with the annual variation (CV) of $14.7 \%-108.9 \%$ and monthly variation (concentration degree) of $0.10-0.71$ in the region. Meanwhile, annual erosivity showed a significant downward trend at an annual decreasing rate mostly above $1.0 \%$. This significantly decreasing trend was mainly attributed to the obvious decline of wind speed during the period. The results suggest that the recent climate changes were highly possible to induce a decrease of wind erosion risk in China's dryland region.
\end{abstract}

Keywords: wind erosion climatic erosivity; trend; climate change; dryland region; China

\section{Introduction}

Wind erosion is a major environmental problem in dryland areas, which causes land degradation (Funk et al., 2004; Lal, 1993) and affects regional development (Yang et al., 2005). In China, about one-third of the territory, which is distributed in the dryland region, is suffering from serious land desertification $(\mathrm{Ci}$ and $\mathrm{Wu}, 1997)$. As a part of the global drylands that are more sensitive to climate changes (Feng and Fu, 2013; Huang et al., 2012), China's dryland region showed various changes in temperature, precipitation, wind speed and other climatic factors during the past decades (Fan et al., 2012; Ge et al., 2013; Meng et al., 2013; Wang et al., 2006; Zhao, 2013). These changes are expected to influence the wind erosion risk, as

Received: 2015-04-23 Accepted: 2015-11-30

Foundation: National Basic Research Program of China, No.2012CB955304

Author: Yang Fengbo (1985-), PhD, specialized in climate change and soil erosion. E-mail: yangfengbo11@126.com

*Corresponding author: Lu Changhe (C.H. Lu), Professor, E-mail: luch@igsnrr.ac.cn 
climatic elements are somewhat decisive factors of wind erosion, especially in dry, sparsely vegetated soils and typically dry regions (Pouyan et al., 2011). In particular, wind speed and precipitation play a more determinant role, which have been recognized as the main determinants of wind erosion climatic erosivity in the arid and semi-arid areas of China (Dong and Kang, 1994; Shen et al., 2006; Yang et al., 2012).

To detect the effect of climate changes on wind erosion needs a model to build linkages with climatic factors. Several such models are available, among which the WEQ developed by Woodruff and Siddoway (1965) and later revised version of RWEQ (Fryrear et al., 1998; Hagen, 1996) are well-known and widely used. These models need detailed inputs of climate, soil, land cover and land management data, and are normally applied at field or small regional scale, whereas generally not suitable for large regional analysis of wind erosion due to limitation of data availability. Instead, climatic factor $\mathrm{C}$, as often called index of wind erosion climatic erosivity, could be an optional choice to measure the climatic tendency to produce conditions conducive to wind erosion (Skidmore, 1986). Several algorithms have been developed for the C-factor, of which the FAO equation (FAO, 1979), a revised version of Chepil (1962) model, is often used because of its simplicity to obtain a reliable estimation compared to physically based complicated models (Skidmore, 1986). This equation is formulated as a function of average wind speed and soil moisture, on the basis that the rate of particle movement is proportional to the cube of average wind speed (Bagnold, 1943) and that soil erodibility varies inversely with the square of water content in the upper few millimeters of soil (Skidmore, 1986). In the Chepil model, the Thornthwaite's index, PE (Thornthwaite, 1931), i.e., the ratio of monthly precipitation to evaporation (Chepil, 1962) is used to indicate the soil water content. As the PE index approaches zero when precipitation approaches zero, as in arid regions, the C-factor approaches infinity (Woodruff and Armbrust, 1968). FAO (1979) solved this problem by replacing the PE index with the ratio of moisture deficit (potential evaporation minus rainfall) to potential evaporation. By this revision, the $\mathrm{C}$-factor depends only on wind velocity when rainfall amount approaches zero, while it is zero when rainfall amount is equal to the potential evaporation.

The aim of this study is to detect the effect of recent changes in climate characteristics on wind erosion risk in China's dryland region, using the $\mathrm{C}$-factor as an indicator. With this aim, the annual C-factor was firstly estimated using the FAO equation from daily/monthly meteorological data during 1961-2012, and the spatiotemporal variation was then analyzed using statistical, spatial interpolation and GIS technologies. Further, long-term changing trend and amplitude in the annual C-factor values were detected using the Mann-Kendall and Sen's slope estimator to reveal its responses to climate changes, and finally main factors affecting the climatic erosivity were identified by sensitivity analysis.

\section{Data and methods}

\subsection{Study area}

The China's dryland region, located between $69.4^{\circ}-128.0^{\circ} \mathrm{E}$ and $27.2^{\circ}-51.1^{\circ} \mathrm{N}$, has an area of 5.58 million $\mathrm{km}^{2}$, covering the Tibetan Plateau, the Loess Plateau and the Inner Mongolia Plateau, and the Taklimakan Desert, the Gurbantunggut Desert, and the Badain Jaran Desert, with 12 provincial administrative units involved (Figure 1) (Yang and Lu, 2015). The region 
has an annual mean temperature of $-3.7-13.6^{\circ} \mathrm{C}$ and precipitation of $33-623 \mathrm{~mm}$. Due to monsoon influence, the annual precipitation has a proportion of $61.8 \%-76.1 \%$ falling in the rainy season of June to September, and increases from west to east with a decrease in the distance to the sea. Based on humidity index $(\mathrm{K})$, the ratio of annual precipitation to potential evapotranspiration, the region was divided into arid, semi-arid and sub-humid zones (Figure 1). The arid zone including the hyper-arid $(\mathrm{K}<0.2)$ has an annual precipitation generally less than $200 \mathrm{~mm}$, covering the major part of Xinjiang, northern Tibetan Plateau and western Inner Mongolia Plateau. The semi-arid zone $(0.2 \leqslant \mathrm{~K}<0.5)$ has an annual precipitation normally between 200 and $450 \mathrm{~mm}$, including southeastern Tibetan Plateau, northern Loess Plateau, eastern Inner Mongolia, and northern Xinjiang. The sub-humid zone $(K \geqslant 0.5)$ is located in the eastern and southeastern part with an annual precipitation mostly above 450 $\mathrm{mm}$.

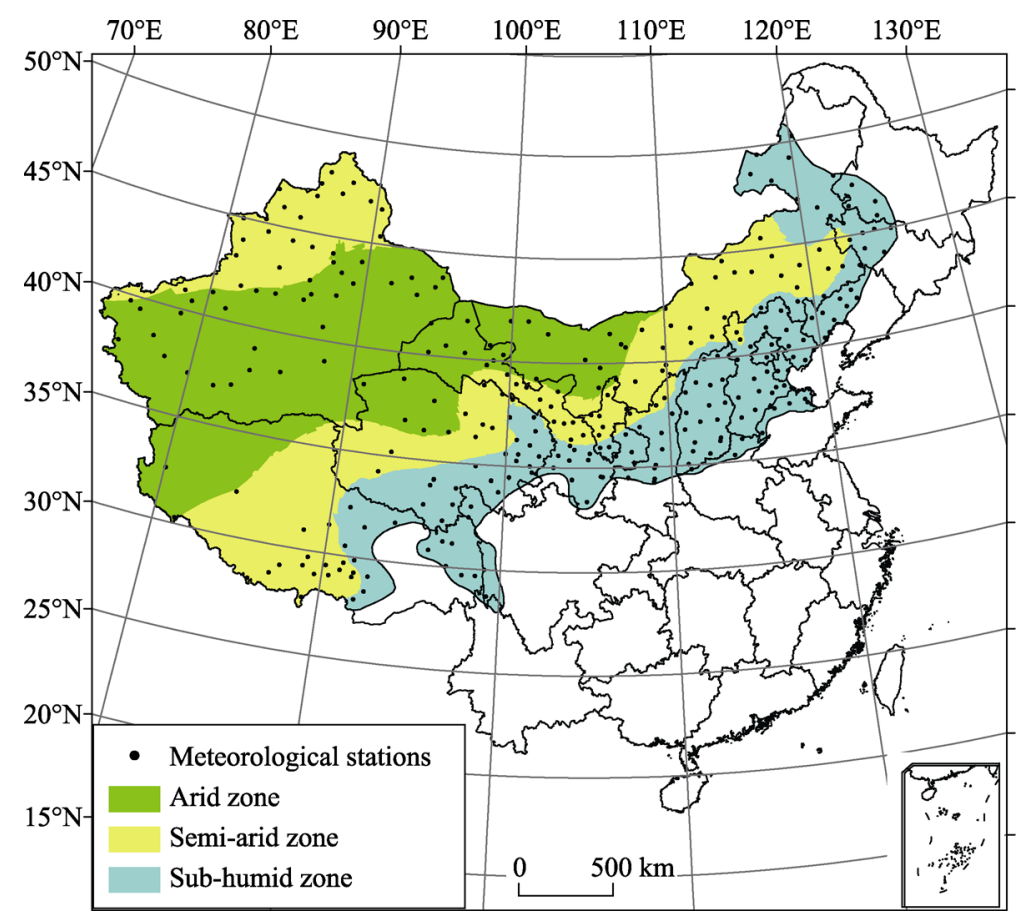

Figure 1 Distribution of meteorological stations and the three climate zones in China's dryland region

\subsection{Data sources}

Daily weather data including precipitation, maximum and minimum temperature, sunshine duration, wind speed, and relative humidity were collected from the National Meteorological Information Centre of China (http://cdc.cma.gov.cn) for the study period of 1961-2012 at 298 meteorological stations in the study area, of which 237 stations have complete records for 52 years, 8 for 50-51 years, 12 for 40-48 years, and 12 for 30-39 years. The remaining 29 stations have a short observation span of 20-28 years (24 stations), 10-14 years (4 stations) and 7 years (1 station), which are mainly located in the arid northwestern part and the Tibetan Plateau where meteorological stations are sparsely distributed. The data records were checked for their homogeneity using the Standard Normal Homogeneity Test 
(Alexandersson, 1986), as done in the previous study of the authors (Yang and Lu, 2015), which selected the annual precipitation as an indicator to have examined the consistence of data records by comparing the yearly values with four highly correlated reference series from the surrounding stations. At 290 stations including 237 stations that have similar observation span of 50-52 years, the data records have passed the homogeneity test. In this study, the temporal variation and trend analysis of annual erosivity were based on data at the 237 stations, while the mean annual climatic erosivity and its spatial variation were based on data at all the 298 stations.

\subsection{Method for climatic erosivity estimation}

Wind erosion climatic erosivity, as indicated by the climatic factor $\mathrm{C}$, was calculated with the FAO equation (FAO, 1979):

$$
C=\frac{1}{100} \sum_{i=1}^{12} u_{i}^{3}\left(\frac{E T P_{i}-P_{i}}{E T P_{i}}\right) d
$$

where $u$ is the mean monthly wind speed at $2 \mathrm{~m}$ height $(\mathrm{m} / \mathrm{s}), P$ is the monthly precipitation $(\mathrm{mm})$ and $d$ is the total number of days in month $i$. ETP is the monthly potential evapotranspiration ( $\mathrm{mm}$ ), as a summation of daily value calculated with Penman-Monteith equation (Allen et al., 1998) using daily data. Daily solar radiation was estimated using the Angstrom equation (Angstrom, 1924): $\mathrm{R}_{\mathrm{a}}=\mathrm{R}_{\mathrm{s}}(a+b \cdot \mathrm{n} / \mathrm{N})$, where $\mathrm{R}_{\mathrm{a}}$ and $\mathrm{R}_{\mathrm{s}}$ are terrestrial surface and extraterrestrial radiation, and $\mathrm{n}$ and $\mathrm{N}$ are the observed and maximum possible daily sunshine duration, respectively. The coefficients $a$ and $b$ were set to 0.18 and 0.55 , based on Li et al. (2004).

\subsection{Evaluation of spatiotemporal variation of climatic erosivity}

Two indices were applied to evaluate the temporal variation of $\mathrm{C}$-factor value at the 237 stations, including coefficient of variation (CV) and concentration degree (CCD). The CV was used to indicate the relative annual variation rate, and expressed in percent of the standard deviation of the annual $\mathrm{C}$-factor value to the average of observation period. The CCD index was applied to measure monthly variation of the C-factor value and computed with Eq. (2), which has a value of 0-1 (Zhang and Qian, 2003; Zheng and Liu, 2003). The higher the index is, the bigger the monthly variation of erosivity. When the index approaches zero, the annual erosivity is uniformly distributed in each month, and when it equals 1 , the erosivity is concentrated in one month.

$$
C C D_{i}=\sqrt{\left(\sum_{j=1}^{N} r_{i j} \times \sin \theta_{j}\right)^{2}+\left(\sum_{j=1}^{N} r_{i j} \times \cos \theta_{j}\right)^{2}} / R_{i}
$$

where $R_{i}$ is the annual $\mathrm{C}$-factor value in the year $i, r_{i j}$ is the $\mathrm{C}$-factor value in month $j$ of the year $i$, and $\theta_{j}$ is the direction angle of monthly erosivity vector in month $j$, equaling $(j-1) \times$ $30^{\circ}$, i.e., for January $(j=1), \theta_{1}=0^{\circ}$, and for December $(j=12), \theta_{12}=330^{\circ}$, according to Zhang and Qian (2003).

The spatial distribution of $\mathrm{CV}$ and $\mathrm{CCD}$ was interpolated and mapped with the Inverse Distance Weighted (IDW) method using the point value at the 237 sites. Considering that stations are very sparse, the mean annual erosivity was interpolated using the mean value at 
the 298 sites, which was obtained by averaging annual values of observation years without considering difference in the duration. The regional average of mean annual erosivity was obtained by averaging the grid value using the Geostatistical Analyst tools in ArcGIS.

\subsection{Estimation of trend and change rate in annual climatic erosivity}

The trend and change rate (the trend amplitude) of annual C-factor values were evaluated for each of the 237 stations, using two widely used nonparametric test methods, the Mann-Kendall test (Kendall, 1975; Mann, 1945) and the Sen's slope estimator (Gilbert 1987; Sen, 1968). The evaluation was performed using MAKESENS, a combined Excel template application of the two methods, as developed by Salmi et al. (2002). With the MAKESENS, the normal approximation $\mathrm{Z}$ test value and slope value $\mathrm{Q}$ of the annual $\mathrm{C}$-factor were calculated for each station. The $Z$ test value was used in the Mann-Kendall to determine whether the annual C-factor values have an upward (positive) or downward (negative) trend at a specific significance level. At $\sigma$ level of significance, a null hypothesis is rejected if the absolute $Z$ value is greater than $Z_{1-\sigma / 2}$, where $Z_{1-\sigma / 2}$ is obtained from the standard normal cumulative distribution tables (Salmi et al., 2002). The Q value, i.e., the Sen's slope as a change in measurement per change in time, indicates the trend amplitude per year in annual C-factor value. In this study, the change rate was presented as percent of the annual mean $\mathrm{C}$-factor value of observation period. The trend and change rate for climatic factors of wind speed, precipitation, temperature and sunshine duration were evaluated with the same methods.

\subsection{Sensitivity analysis}

Wind erosion climatic erosivity is representative of the integrated effect of climatic factors, such as wind speed, precipitation and temperature. Therefore, any change of climatic factors could lead to a corresponding change of climatic erosivity (Goyal, 2004). For a specific climate factor, the contribution to the $\mathrm{C}$-factor value can be quantified by calculating the sensitivity coefficient under condition that other parameters are fixed. The sensitivity coefficient of the C-factor value to climatic variable $x, S_{\mathrm{x}}$, was calculated with first-order Taylor series approximation (McCuen, 1974):

$$
S_{\mathrm{x}}=\frac{\Delta C}{\Delta x} \cdot \frac{x}{C}
$$

where $\Delta C$ is the relative change rate $(\%)$ of the $\mathrm{C}$-factor value, induced by the relative change (\%) in climatic factor $x, \Delta x$. A positive or negative $S$ value indicates that the behavior of $C$ is consistent with or contrary to the behavior of input factors (Gong et al., 2006; Yin et al., 2010). In this study, the sensitivity coefficient was calculated for each climatic factor by assuming a change of $\pm 20 \%$ and $\pm 10 \%$ in the value, respectively.

\section{Results}

\subsection{Spatial distribution of annual climatic erosivity}

Mean annual C-factor value during 1961-2012 was between 2 and 166 at 292 stations and 229-471 at 6 stations, showing an obvious spatial variation (Figure 2). At 135 stations mainly distributed in the southern part and southwestern Xinjiang, which cover $30.2 \%$ of the 


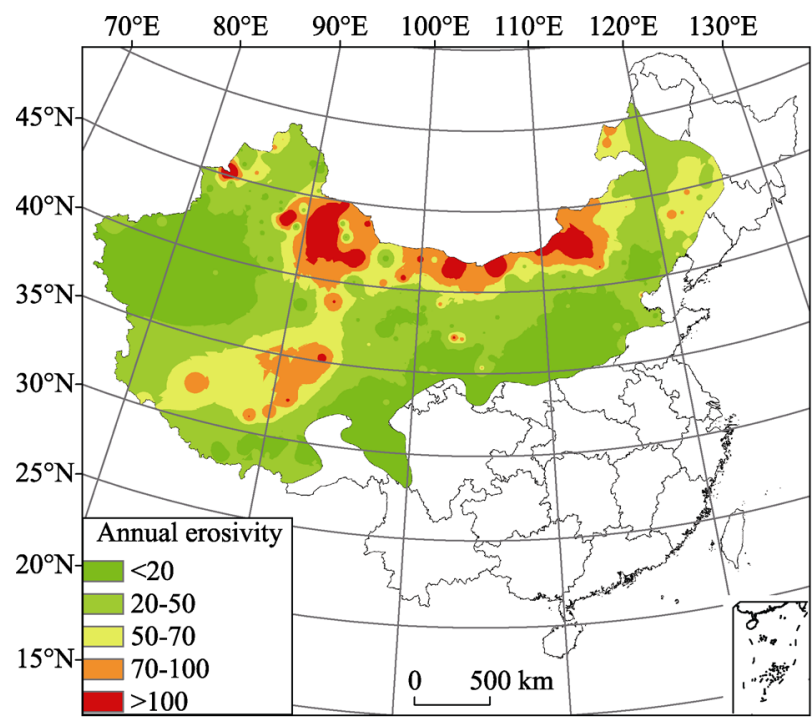

Figure 2 Spatial distribution of mean annual C-factor values in the study area region, the climatic erosivity was very weak with the $\mathrm{C}$-factor value generally less than 20. At 67 stations, which are concentrated in the north-central part and around the middle of the northern Tibetan Plateau, and represent $31.4 \%$ of the region, the climatic erosivity was strong with the $\mathrm{C}$-factor value exceeding 50. The remaining 96 stations or $38.4 \%$ of the region showed a moderate climatic erosivity with the $\mathrm{C}$-factor value mostly between 20 and 50 .

The weighted regional average annual C-factor value was 39.4 for the whole region, and 56.2, 48.1 and 24.6 for the arid, semi-arid

and sub-humid zone, respectively, decreased with an increase in humidity. Of the three plateaus, the Inner Mongolia Plateau, a region being suffered from serious wind erosion and desertification problem, showed a significantly higher value (mostly exceeding 50), while the Loess Plateau that is well acknowledged by its serious water erosion, exhibited a lower value (mostly below 40). In the Tibetan Plateau, the C-factor value was mostly between 40 and 70 , with the regional average of about 50, showing a moderate risk of wind erosion. In southern Xinjiang where the Taklamakan Desert is located, the climatic erosivity was very weak (mostly less than 20) due to low wind speed, although it has an extremely dry climate with an annual precipitation generally below $50 \mathrm{~mm}$. As for different vegetation types, we estimated the mean C-factor value, based on the vegetation map of China (http://www. geodata.cn) using the spatial analysis tools in ArcGIS. It was found that desert, steppe and bare-land types showed a higher climatic erosivity, with the mean C-factor value of 53.9, 46.0, and 40.3, respectively. The cropland, alpine meadow, and forest-shrub types showed a lower value of $33.8,33.8$ and 26.4 , respectively.

\subsection{Annual and monthly variation of climatic erosivity}

Relative variation (CV) of the annual C-factor values varied from $13.7 \%$ to $108.9 \%$, differed greatly over the region. In Xinjiang, southwestern Qinghai, and northeastern part of the region, annual climatic erosivity varied more apparently with the CV mostly exceeding $40 \%$ (Figure 3). While in southern Tibet, western Inner Mongolia, eastern Qinghai, and southern Loess Plateau, the CV was much lower, mostly less than $30 \%$.

Monthly variation of climatic erosivity was obvious and differed markedly over spatial, as observed from the monthly distribution of the $\mathrm{C}$-factor value at three selected stations in Figure 4, which indicates a much different pattern of monthly variation among the three climatic zones. In the arid zone, climatic erosivity was strong in November to April and weak in summer months (Figure 4b), in the semi-arid zone, erosivity was strong in spring and 
and week in summer (Figure 4c), and in the sub-humid zone, erosivity was significantly lower in autumn than the other seasons (Figure 4d). This spatial variation was further demonstrated in Figure 5 with the CCD index of annual climatic erosivity. It can be seen that monthly erosivity variation was relatively low in the north central, but much higher in southern Tibetan Plateau and northern Xinjiang, and was largely between 0.35 and 0.45 in the remaining areas. This spatial distribution was generally in an opposite trend compared to that of annual erosivity (Figure 2), i.e., the lower

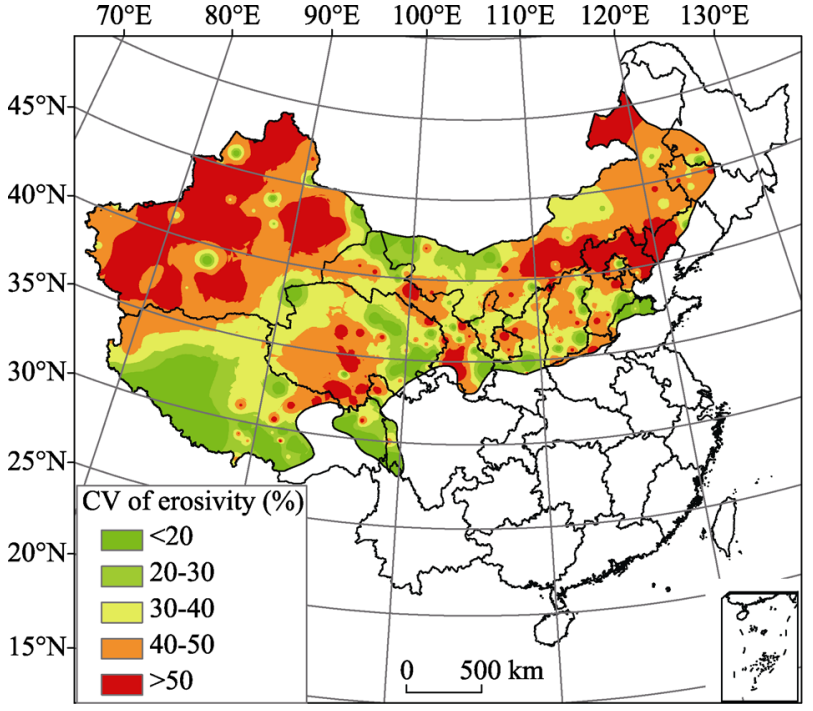

Figure 3 Spatial distribution of annual variation rate $(\mathrm{CV})$ of C-factor value during 1961-2012 CCD or lower monthly variation was generally associated with higher climatic erosivity.
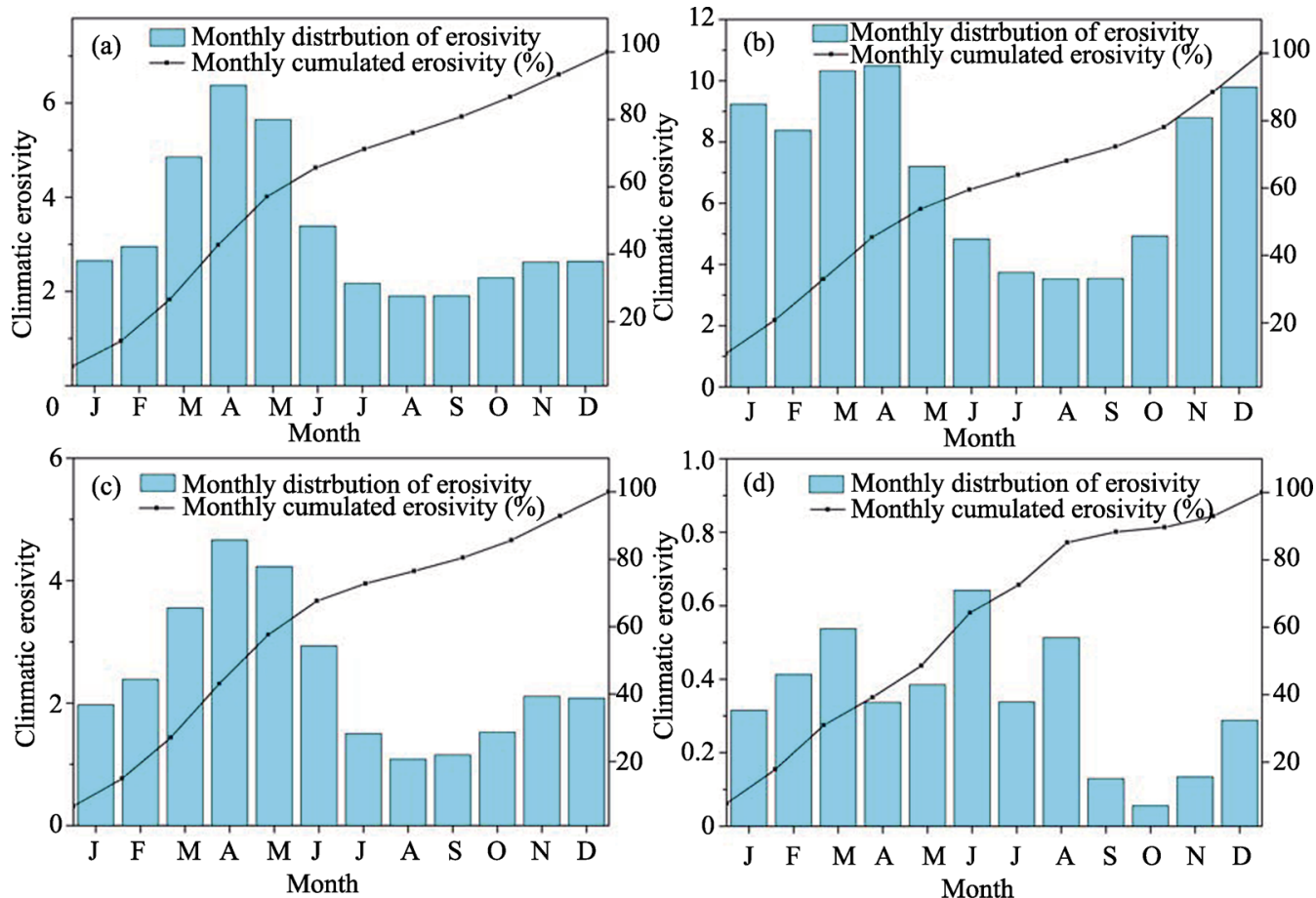

Figure 4 Monthly distribution of mean annual C-factor value for the whole region (a), Yumen in the arid zone (b), Baotou in the semi-arid zone (c), and Xi' an in the sub-humid zone (d)

\subsection{Changing trend and amplitude in climatic erosivity}

Table 1 presents the summary trend results for the 237 stations during 1961-2012. At 184 stations or in $93.4 \%$ of the China's dryland region, the annual C-factor value showed a sig- 
nificant downward trend at the 0.05 significance level, and at 29 stations or in $4.9 \%$ of the region, a non-significant decline trend. At 24 stations, mainly distributed in the southern Loess Plateau, it showed a significantly (11 stations) and non-significantly (13 stations) increasing trend. For the whole region, the regional mean erosivity showed a significant downward trend $(Z=-6.79)$, and demonstrated a positive departure from the mean value during the period before the middle 1980s, while a negative departure after then (Figure 6).

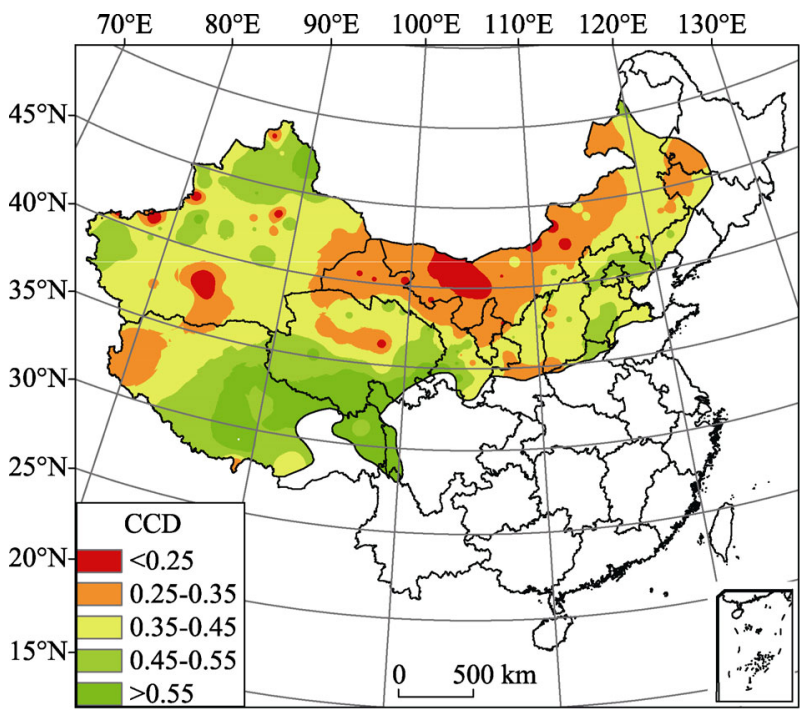

Figure 5 Spatial distribution of monthly variation of mean annual C-factor values as presented by CCD index

Table 1 Variation trend of annual regional climatic erosivity in different regions during 1961-2012

\begin{tabular}{lcccc}
\hline & $\begin{array}{c}\text { Significant } \\
\text { increase }(\mathrm{Z}>1.645)\end{array}$ & $\begin{array}{c}\text { Non-significant } \\
\text { increase } \\
(0<\mathrm{Z}<1.645)\end{array}$ & $\begin{array}{c}\text { Non-significant } \\
\text { decrease } \\
(-1.645<\mathrm{Z}<0)\end{array}$ & $\begin{array}{c}\text { Significant decrease } \\
(\mathrm{Z}<-1.645)\end{array}$ \\
\hline Arid zone & 3 & 4 & 7 & 52 \\
Semi-arid zone & 5 & 1 & 11 & 69 \\
Sub-humid zone & 5 & 6 & 29 & 63 \\
Whole region & 13 & 11 & & 184 \\
\hline
\end{tabular}

The yearly change rate of annual C-factor value during 1961-2012 ranged from $-3.82 \%$ to $1.78 \%$, with the majority ranging between $-2.3 \%$ and $-1.0 \%$ (Figure 7 ), showing a quick decreasing trend in erosivity. In the western and northeastern parts of the region, the climatic erosivity decreased at an annual rate mostly above $1.7 \%$, significantly higher than that in the middle part, particularly in the Loess Plateau where the

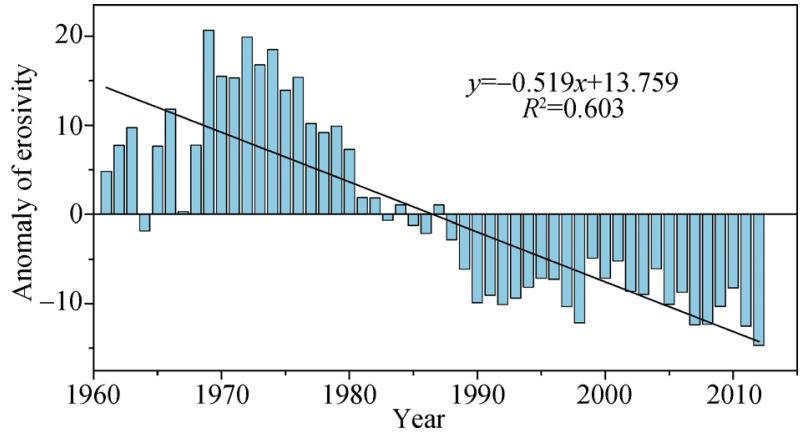

Figure 6 Departure (\%) of annual regional mean C-factor value from the average during 1961-2012 
change rate was obviously lower (Figure 7). For the entire region, the mean erosivity at all stations decreased by $1.39 \%$ per year, which was much higher than $0.53 \%$ in the arid zone, but lower than $1.87 \%$ in the semi-arid zone and $1.89 \%$ in the sub-humid zone.

Taking the middle of the study period as a breakpoint, we computed the average annual $\mathrm{C}$-factor value for the two periods of 1961-1986 and 1987-2012, respectively. The results indicate that the second 26-year's average for the whole region was 30.9 , decreased distinctly by $35 \%$ com-

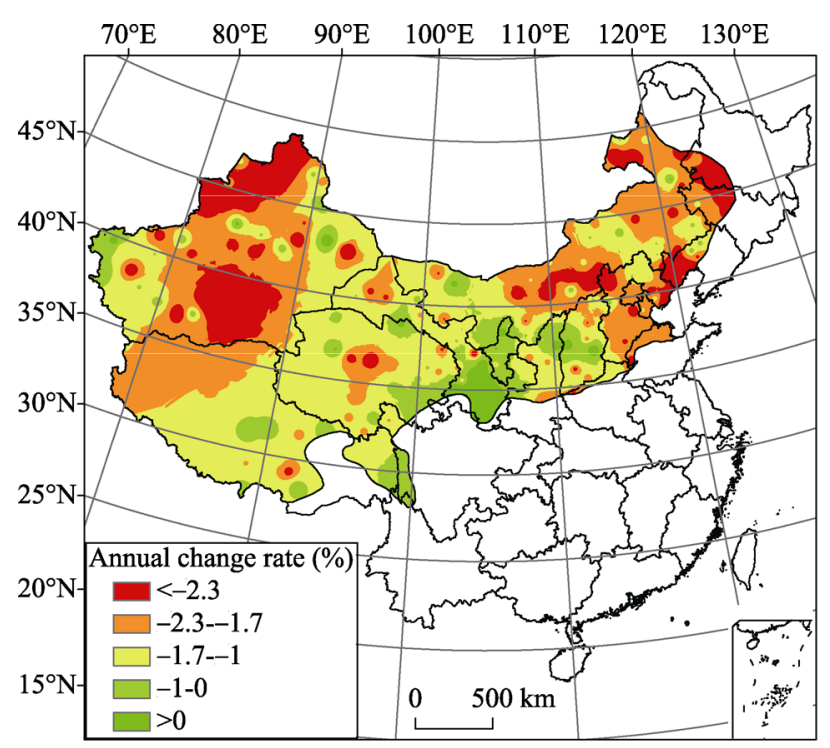

Figure 7 Spatial distribution of annual change rate of the C-factor values during 1961-2012 pared to the average of 47.9 during the first 26 years. For major vegetation types, the erosivity of the steppe areas decreased most significantly by $51.6 \%$, from 66.4 during the first 26 years to 32.1 during the second, followed by the cropland (41.6\%), alpine meadow (39.3\%), forest-shrub (38.5\%), and desert $(25.2 \%)$ areas. This decrease in climatic erosivity illustrates that recent climate changes of the past 50 years could reduce the wind erosion risk in the region, particularly in the steppe vegetation areas where wind erosion is more severe than other areas.

\subsection{Sensitivity of erosivity to climatic factors}

We calculated the sensitivity coefficient of $\mathrm{C}$-factor value to the major climate factors for each of the 237 stations, with the regional average results for the whole region and the three climate zones presented in Table 2 . It can be seen that climatic erosivity was positively proportional to wind speed (WS), daily maximum $\left(\mathrm{T}_{\max }\right)$ and minimum $\left(\mathrm{T}_{\min }\right)$ temperature, and sunshine duration (SD), but was inversely proportional to relative humidity (RH) and precipitation (P). At site level, wind speed was the most sensitive variable and the sensitivity coefficient was 3.03-3.35 for all stations, meaning that a change of one percent in wind speed could lead to a change of more than three percent in the $\mathrm{C}$-factor. Precipitation and relative humidity were the next sensitive variables and the sensitivity coefficient at site level was between -1.46 and -0.01 . The $\mathrm{C}$-factor value was not sensitive to temperature and sunshine duration. For the regional mean erosivity, the sensitivity coefficient to wind speed was 3.06-3.12, and to other factors, it was between -0.35 and 0.15 (Table 2). These results imply that the climate factors except wind speed had a very weak influence on the climatic erosivity. For monthly erosivity, the sensitivity coefficient from July to October was much higher than that in other months, particularly the sensitivity to precipitation and relative humidity (Figure 8). 
Table 2 Sensitivity coefficients of the regional mean C-factor value to various climate factors

\begin{tabular}{lllllll}
\hline \multicolumn{1}{c}{ Region } & $\mathrm{S}_{\mathrm{WS}}$ & $\mathrm{S}_{\mathrm{RH}}$ & $\mathrm{S}_{\mathrm{Tmax}}$ & $\mathrm{S}_{\mathrm{Tmin}}$ & $\mathrm{S}_{\mathrm{SD}}$ & $\mathrm{S}_{\mathrm{P}}$ \\
\hline Arid zone & 3.06 & -0.08 & 0.03 & 0.01 & 0.02 & -0.12 \\
Semi-arid zone & 3.09 & -0.16 & 0.09 & 0.03 & 0.04 & -0.22 \\
Sub-humid zone & 3.12 & -0.24 & 0.15 & 0.04 & 0.07 & -0.35 \\
Whole region & 3.09 & -0.18 & 0.09 & 0.03 & 0.05 & -0.26 \\
\hline
\end{tabular}

During 1961-2012, the regional mean wind speed was decreased by $24.4 \%$, relative humidity by $2.9 \%$, precipitation by $2.2 \%$ and sunshine duration by $6.3 \%$, while the maximum and minimum temperature was increased by $8.7 \%$ and $85.7 \%$, respectively. These changes comprehensively resulted in a reduction of $52.0 \%$ in the regional mean climatic erosivity. An analysis revealed that change in wind speed and sunshine duration reduced the erosivity by $58.2 \%$ and $0.3 \%$, while change in the relative humidity, precipitation, and maximum

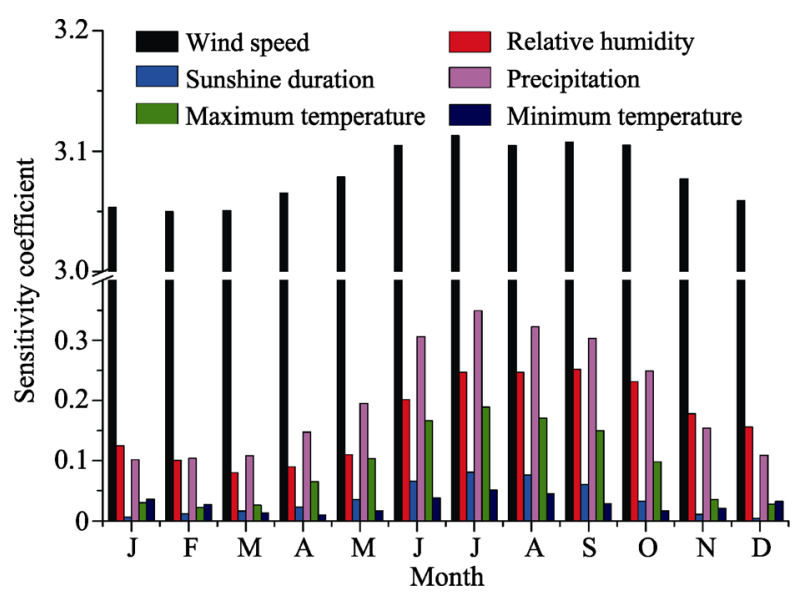

Figure 8 Monthly distribution of sensitivity coefficients of the regional mean annual $\mathrm{C}$-factor value to major climate factors

and minimum temperature increased the erosivity by $0.5 \%, 0.6 \%, 0.8 \%$ and $4.6 \%$, respectively. Therefore, the reduction of climatic erosivity was mainly caused by the decline in wind speed.

\section{Discussion}

The mean annual erosivity ranged 2-471 and mostly between 2 and 166 over the region. An earlier study for the arid and semi-arid zones of China using data of 1951-1980 indicates that the climatic erosivity was mostly between 10 and 100 (Dong and Kang, 1994). Two previous studies evaluated climatic erosivity for western Inner Mongolia during 1963-2003 (Wang et al., 2005) and for the Tarim Basin during 1961-2007 (Yang et al., 2012), indicating a regional mean value of 154.5 and 17.5 , respectively. In the three studies, the climatic erosivity was estimated all using the FAO equation, but the potential evapotranspiration (ETP) was computed using a simple method based on two factors of monthly mean temperature and relative humidity, as proposed by Cheng (1980). For comparison, we calculated climatic erosivity for all stations in the region using this simple ETP equation, finding that the estimated values were averagely $11 \%$ higher than the erosivity as presented in this study. This implied that the climatic erosivity was rather sensitive to the ETP value. As the Penman-Monteith equation is widely accepted for accurate estimation of EPT, it is suggested that estimation of climatic erosivity with FAO model should be better based on this equation. 
Wind speed was recognized as the determinant contributor to climatic erosivity, and other climate factors such as temperature and precipitation had minor influences in the region. A linear regression analysis indicates that mean annual erosivity at site level was significantly related to mean annual wind speed $\left(\mathrm{R}^{2}=0.94\right)$, implying that the spatial distribution of erosivity was highly in accordance with that of wind speed. These findings are consistence with the results of previous studies (Dong and Kang, 1994; Wang et al., 2005).

Climatic erosivity was distinctively declined in the region's majority during 1961-2012, and in total, it was decreased by $52 \%$ for the regional average during the period. This decrease was mainly caused by decline of wind speed, as indicated in Section 3.4. During the past 50 years, wind speed in the region showed a significant decline, with the regional average of annual wind speed decreased by $24.4 \%$. Similar wind decline trend during the past decades has been observed in many parts of the world, such as northeastern and central China (Ren et al., 2005; Vautard et al., 2010; Wang et al., 2004), North America (Pryor et al., 2009; Tuller, 2004), European countries (Brazdil et al., 2009; Dadaser-Celik and Cengiz, 2014; McVicar et al., 2010), and Australia (McVicar et al., 2008). Over almost all continental areas in the northern mid-latitudes, surface wind speeds have been observed a decline of 5\%-15\% during 1979-2008 and strong winds have slowed faster than weak winds (Vautard et al., 2010). The causes of wind decrease were recognized to include weakness of continental cold high pressure (Klink, 2007; You et al., 2010), decrease in pressure gradient (Tuller, 2004), and changes in surface roughness by e.g., vegetation increases and other human activities (Vautard et al., 2010). For our study area, vegetation restoration by the ecological restoration during recent 15 years may have a contribution to the wind decrease, particularly in the hilly Loess Plateau (Li and Lu, 2015).

The results of this study provide a preliminary perspective on the effect of recent climate changes on wind erosion risk in China's drylands region. Due to wind speed decline, the climatic erosivity showed an obvious decreasing trend in the region, implying that the wind erosion intensity could be possibly reduced during the past 50 years. As the analyses in this study were based on only one simple index of the $\mathrm{C}$-factor, not considering land surface conditions of soil, vegetation, relief and management practices, it should be deemed as a preliminary estimation of possible effects of changes in climate characteristics on wind erosion risk during the past half century. Further studies at small regional scales are needed by incorporating all factors influencing wind erosion.

\section{Conclusions}

This study presents spatiotemporal variations and trend of wind erosion climatic erosivity in China's dryland region, with the main conclusions summarized below:

(1) Mean annual climatic erosivity was 2-471 (mostly 2-166) in China's dryland region. The spatial distribution of erosivity was highly in accordance with spatial changes in wind speed, and showed a decreasing trend with an increase in humidity from arid to semi-arid and to sub-humid zone. Climatic erosivity was significantly higher in northwestern Inner Mongolia Plateau, while it was lower in the southern zone of the region and the desert area in southern Xinjiang.

(2) Annual variation rate (CV) of climatic erosivity during 1961-2012 was $13.7 \%$ - 
$108.9 \%$, and monthly variation as indicated by the index of concentration degree was between 0.10 and 0.71 over the region. Both variation coefficients showed an opposite spatial changing trend compared to that of annual climatic erosivity.

(3) More than $90 \%$ of the region showed a significantly decreasing trend in annual climatic erosivity during 1961-2012, with a small area mainly distributed in the southwestern Loess Plateau showing an increasing trend. For the entire region, the mean annual erosivity declined significantly by $1.39 \%$ per year, and for the arid, semi-arid and sub-humid zone, it decreased by $0.53 \%, 1.87 \%$ and $1.89 \%$ per year, respectively.

(4) Wind speed was the most sensitive and determinant factor of climatic erosivity, while precipitation, relative humidity and temperature had a minor influence. It is found that the regional mean wind speed was decreased by $24.4 \%$ during $1961-2012$, reduced the erosivity by $58.2 \%$. Changes in temperature (rising), and precipitation and humidity (decreasing) increased the erosivity by $1.1 \%$ and $5.1 \%$, respectively. The combined effect of changes in those factors was rather close to the total reduction of $52.0 \%$ in the region's mean erosivity during the period.

(5) This study provides a preliminary estimation of recent climate changes on wind erosion risk in China's drylands region, indicating an obvious decrease in the wind erosion climatic erosivity, and thus a reduction in wind erosion risk. Further studies are needed at site or small regional level by considering all factors influencing wind erosion.

\section{References}

Alexandersson H, 1986. A homogeneity test applied to precipitation data. Journal of Climatology, 6(6): 661-675.

Allen R G, Pereira L S, Raes D et al., 1998. Crop Evapotranspiration: Guidelines for Computing Crop Water Requirements. Rome: United Nations Food and Agriculture Organization.

Angstorm A, 1924. Solar and terrestrial radiation. Report to the international commission for solar research on actinometric investigations of solar and atmospheric radiation. Quarterly Journal of the Royal Meteorological Society, 198(1): 140-141.

Bagnold R W, 1943. The Physics of Blown Sand and Desert Dunes. London: Methuen.

Brazdil R, Chroma K, Dobrovolny P et al., 2009. Climate fluctuations in the Czech Republic during the period 1961-2005. International Journal of Climatology, 29(2): 223-242.

Cheng Tianwen, 1980. Determination and Calculation Method of Field Evaporation and Evaporation Power. Beijing: Science Press.

Chepil W S, 1962. Climatic factor for estimating wind erodibility fields. Journal of Soil and Water Conservation, 17(4): 162-165.

$\mathrm{Ci}$ Longjun, $\mathrm{Wu} \mathrm{Bo}, 1997$. Climatic type division and the potential extent determination of desertification in China. Journal of Desert Research, 17(2): 107-111. (in Chinese)

Dadaser-Celik F, Cengiz E, 2014. Wind speed trends over Turkey from 1975 to 2006. International Journal of Climatology, 34(6): 1913-1927.

Dong Yuxiang, Kang Guoding, 1994. Study on the wind erosion climatic erosivity in arid and semi-arid areas in China. Journal of Soil and Water Conservation, 8(3): 1-7. (in Chinese)

Fan Lan, Lu Changhe, Yang Biao et al., 2012. Long-term trends of precipitation in the North China Plain. Journal of Geographical Sciences, 22(6): 989-1001.

FAO, 1979. A provisional methodology for soil degradation assessment. Rome.

Feng Song, Fu Qiang, 2013. Expansion of global drylands under a warming climate. Atmospheric Chemistry and Physics, 13(19): 10081-10094.

Fryrear D W, Saleh A, Bilbro J D et al., 1998. Revised Wind Erosion Equation (RWEQ). Wind Erosion and Water 
Conservation Research Unit, USDA-ARS. Southern Plains Area Cropping System Research Laboratory, Technical Bulletin No.1.

Funk R, Skidmore E L, Hagen L J, 2004. Comparison of wind erosion measurements in Germany with simulated soil losses by WEPS. Environmental Modelling \& Software, 19(17): 177-183.

Ge Quansheng, Wang Huanjiong, Dai Junhu, 2013. Shifts in spring phenophases, frost events and frost risk for woody plants in temperate China. Climate Research, 57(3): 249-258.

Gong Lebing, Xu Chongyu, Chen Deliang et al., 2006. Sensitivity of the Penman-Monteith reference evapotranspiration to key climatic variables in the Changjiang (Yangtze River) basin. Journal of Hydrology, 329(3\&4): 620-629.

Goyal R K, 2004. Sensitivity of evapotranspiration to global warming: A case study of arid zone of Rajasthan (India). Agricultural Water Management, 69(1): 1-11.

Hagen L J, Wagner L E, Tatarko J, 1996. Wind erosion prediction system (WEPS). Technical Documentation.Beta Release 95-08. U.S. Department of Agriculture: Washington DC.

Huang Jianping, Guan Xiaodan, Chou Jifan, 2012. Enhanced cold-season warming in semi-arid regions. Atmospheric Chemistry and Physics, 12(2): 5391-5398.

Jiang Zhihong, Huang Qun, Li Qingxiang, 2008. Study of precipitation series homogeneous adjustment and their correction over China in the last 50 years. Climatic and Environmental Research, 13(1): 67-74.

Kendall M G, 1975. Rank Correlation Methods.London: Griffin.

Khaliq M N, Ouarda T B M J, 2007. On the critical values of the standard normal homogeneity test (SNHT). International Journal of Climatology, 27(5): 681-687.

Klink K, 2007. Atmospheric circulation effects on wind speed variability at turbine height. Journal of Applied Meteorology and Climatology, 46(4): 445-456.

Lal R, 1993. Tillage effects on soil degradation, soil resilience, soil quality, and sustainability: Introduction. Soil \& Tillage Research, 27(1-4): 1-8.

Li Jun, Shao Mingan, Zhang Xingchang, 2004. Data base construction for the EPIC model on the Loess Plateau region. Journal of Northwest A\&F University (Natural Science Edition), 32(8): 21-26. (in Chinese)

Li Wangjun, Lu Changhe, 2015. Aridity trend and response to vegetation restoration in the loess hilly region of northern Shaanxi Province. Journal of Geographical Sciences, 25(3): 289-300.

Liu Xiaoning, Sun Anjian, 1995. An inhomogeheity test study of annual precipitation series. Meteorological Monthly, 21(8): 3-6. (in Chinese)

Mann H B, 1945. Nonparametric tests against trend. Econometrica, 13(3): 245-259.

McCuen R H, 1974. A sensitivity and error analysis of procedures used for estimating evaporation. Water Resour. Bull., 10(3): 486-498.

McVicar, T R, Van Niel T G, Li Ningtao et al., 2008. Wind speed climatology and trends for Australia, 1975-2006: Capturing the stilling phenomenon and comparison with near-surface reanalysis output. Geophysical Research Letters, 35(20): L20403.

McVicar T R, Van Niel T G, Roderick M L et al., 2010. Observational evidence from two mountainous regions that near-surface wind speeds are declining more rapidly at higher elevations than lower elevations: 1960-2006. Geophysical Research Letters, 37(6): L06402.

Meng Xiujing, Zhang Shifeng, Zhang Yongyong et al., 2013. Temporal and spatial changes of temperature and precipitation in Hexi Corridor during 1955-2011. Journal of Geographical Sciences, 23(4): 653-667.

Pouyan S, Ganji A, Behnia P, 2011. Regional analysis of wind climatic erosivity factor: A case study in fars province, southwest Iran. Theoretical and Applied Climatology: 105(3): 1-10.

Pryor S C, Barthelmie R J, Young D T et al., 2009. Wind speed trends over the contiguous United States. Journal of Geophysical Research-Atmospheres, 114(D14): 14105.

Ren Guoyu, Guo Jun, Xu Mingzhi et al., 2005. Climate changes of China's mainland over the past half century. Acta Meteorologica Sinica, 63(6): 942-956. (in Chinese)

Salmi T, Maata A, Antilla P et al., 2002. Detecting trends of annual values of atmospheric pollutants by the Mann-Kendall test and Sen's slope estimates: The Excel template application Makesens. Finnish 
Meteorological Institute, Helsinki, Finland.

Shen Xiangdong, Zhang Yajing, Li Xiaoli, 2006. Analysis on the relationship between soil desertification and character of climate in the north of Inner Mongolia. Journal of Agro-Environment Science, 25(6): 1554-1559.

Skidmore E L, 1986. Wind erosion climatic erosivity. Climatic Change, 9(1): 195-208.

Thornthwaite C W, 1931. The climates of North America according to a new classification. Geographical Review, 21(4): 633-655.

Tuller S E, 2004. Measured wind speed trends on the west coast of Canada. International Journal of Climatology, 24(11): 1359-1374.

Vautard R, Cattiaux J, Yiou P et al., 2010. Northern Hemisphere atmospheric stilling partly attributed to an increase in surface roughness. Nature Geoscience, 3(11): 756-761.

Wang Ying, Cao Mingkui, Tao Bo et al., 2006. The characteristics of spatio-temporal patterns in precipitation in China under the background of global climate change. Geographical Research, 25(6): 1031-1040. (in Chinese)

Wang Yong, Zhao Ju, Cheng Yuchen, 2005. Analysis of wind erosion climatic erosivity at agri-pasture transition zone in north area of Yinshan Mountain. Acta Agriculturae Boreali-Sinica, 20(S): 57-60. (in Chinese)

Wang Zunya, Ding Yihui, He Jinhai et al., 2004. An updating analysis of the climate change in China in recent 50 years. Acta Meteorological Sinica, 62(2): 228-236. (in Chinese)

Woodruff, N P, Armbrust, D V, 1968. A monthly climatic factor for wind erosion equation. Journal of Soil and Water Conservation, 23(3): 103-104.

Woodruff N P, Siddoway F H, 1965. A wind erosion equation. Soil Science Society of America Proceedings, 29(5): 602-608.

Yang Fengbo, Lu Changhe, 2015. Spatiotemporal variation and trends in rainfall erosivity in China's dryland region during 1961-2012. Catena, 133(10): 362-372.

Yang Xiaohui, Zhang Kebin, Jia Baoquan et al., 2005. Desertification assessment in China: An overview. Journal of Arid Environments, 63(2): 517-531.

Yang Xinghua, He Qing, Li Hongjun et al., 2012. Calculation and analysis on wind erosion climatic erosivity in the Tarim Basin. Jounal of Desert Research, 32(4): 990-995.

Yin Yunhe, Wu Shaohong, Dai Erfu, 2010. Determining factors in potential evapotranspiration changes over China in the period 1971-2008. Chinese Science Bulletin, 55(29): 3329-3337.

You Qinglong, Shichang Kang, Wolfgang-Albert Flügel et al., 2010. Decreasing wind speed and weakening latitudinal surface pressure gradients in the Tibetan Plateau. Climate Research, 42(1): 57-64.

Zhang Lujun, Qian Yongfu, 2003. Annual distribution features of precipitation in China and their interannual variations. Acta Meteorologica Sinica, 17(2): 146-163.

Zhao Huarong, 2013. Temporal and spatial variations and transition of precipitation in China during 1960-2010. Tropical Geography, 33(4): 414-419. (in Chinese)

Zheng Hongxing, Liu Changming, 2003. Changes of annual runoff distribution in the headwater of the Yellow River Basin. Progress in Geography, 22(6): 585-591. (in Chinese) 